\title{
Noisy information, distance and law of one price dynamics across US cities
}

\author{
Mario J. Crucini ${ }^{a *}$, Mototsugu Shintani, ${ }^{b}$ Takayuki Tsuruga ${ }^{c} \dagger$ \\ ${ }^{a}$ Department of Economics, Vanderbilt University, CAMA, and NBER; \\ ${ }^{b}$ RCAST, The University of Tokyo and Department of Economics, Vanderbilt University; \\ ${ }^{c}$ Graduate School of Economics, Kyoto University and CAMA
}

Received Date; Received in Revised Form Date; Accepted Date

\begin{abstract}
US micro price data at the city level suggests that both the volatility and the persistence of law of one price deviations are rising in the distance between US cities. A standard two-city equilibrium model with trade costs can predict the relationship between volatility and distance but not between persistence and distance. We show that if there is imperfect information about the state of nominal aggregate demand, with noisy signals that are asymmetric across cities, then distance and persistence will be positively correlated. Our main results are shown to be robust to the introduction of sticky prices and multiple cities.

Keywords: Real exchange rates, Law of one price, Relative prices, Trade costs

JEL classification: E31; F31; D40
\end{abstract}

\section{Introduction}

Trade costs still matter even among highly integrated economies. The empirical trade literature has shown a negative relationship between bilateral trade flows and distance to be robust across time and countries (see Disdier and Head, 2008). More recently, Anderson and van Wincoop (2004) survey the empirical literature on the law of one price (LOP) and

${ }^{*}$ Corresponding author: Department of Economics, Vanderbilt University, Nashville, TN 37235-1819, USA. Tel.: +1 615322 7357. E-mail address: mario.crucini@vanderbilt.edu

${ }^{\dagger}$ We thank Jeff Campbell, Virgiliu Midrigan, Ricardo Reis, two anonymous referees, and seminar participants at Kyoto University, the University of Tokyo, Otaru University of Commerce for helpful comments and discussions. Crucini and Shintani gratefully acknowledge the financial support of National Science Foundation (SES-1030164). Tsuruga gratefully acknowledges the financial support of Grant-in-aid for Scientific Research. 


\footnotetext{
${ }^{1}$ For example, these can be obtained either by a variant of a static Ricardian model of Eaton and Kortum (2002) or by the static trade model of Helpman et al. (2008) which emphasizes the self-selection of firms into export markets. See also Kano et al. (2013).
} 
nopolistic competition and (ii) nominal aggregate demand shocks which cannot be common knowledge even in the long-run. Subsequent work by Angeletos and La'O (2009) simplifies the second assumption to the case where shocks will be publicly known after one period and suggest that the introduction of sticky prices into the flexible price model of imperfect common knowledge can improve predictions on inflation and output dynamics.

Following this line of research, we introduce information frictions to explain the persistence and volatility of intra-national LOP deviations. Specifically, we modify the dynamic model of intra-national LOP deviations used in CST by introducing the assumption of heterogeneous expectations about the state of nominal demand across cities in the economy. Analytical result shows that when information precision is heterogenous across cities, our two-city model produces a positive correlation between persistence and distance while preserving the prediction of the positive volatility-distance correlation produced by standard perfect information models. Our results are robust to extensions that include sticky prices or more than two cities.

The paper is organized as follows. Empirical findings from the US price data are explained in Section 2. Section 3 introduces the theoretical model and explores its implications for LOP dynamics. Section 4 reports on robustness analysis. Section 5 concludes.

\section{Regressions}

Using the US data, this section provides evidence on the persistence-distance correlation.

\subsection{Data}

The data are individual prices from the American Chamber of Commerce Researchers Association (ACCRA) Cost of Living Index produced by the Council of Community and Economic Research. The original ACCRA Cost of Living Index includes 75 goods and services across 632 cities. However, when a balanced panel from 1990:Q1 to 2007:Q4 is 
1 constructed, the number of items and cities are reduced to 48 and 52 , respectively. ${ }^{2}$

In measuring the LOP deviations, we follow Crucini and Shintani (2008) and consider all possible city pairs for each good or service. Let $q_{j, k, t}(i)$ be the LOP deviation measured as the difference between the logarithm of the price of good $i$ in city $j$ and that of the same good in city $k$ :

$$
q_{j, k, t}(i)=\ln P_{j, t}(i)-\ln P_{k, t}(i),
$$

2 for $i=1,2, \ldots, 48$ and for all $j, k=1,2, \ldots, 52$ with $j \neq k$. Because the number of cities is 52 , 3 the total number of city pairs is 1,326 in our data set.

\footnotetext{
${ }^{2}$ We closely follow Yazgan and Yilmazkuday (2011) in the construction of panel data. See their paper for the detailed explanation on the selection of items and cities.

${ }^{3}$ We compute the first-order autocorrelation simply by estimating a coefficient in an AR(1) model. For the SAR and the largest AR root, we select lag lengths of AR models based on the Bayesian Information Criterion (BIC).
} 
1 bilateral pairs, $s d_{q}$ is 0.136 and $\operatorname{mapd}_{q}$ is 0.158 . Both of these are close to their counterparts in Parsley and Wei (1996), suggesting some robustness of these measures over time.

\section{[Locate Table 1 about here.]}

Table 1 also reports persistence and volatility measures of LOP deviations for city pairs whose locations are very close and far apart. The fourth to sixth rows of the table report the persistence and volatility for 13 city pairs in which the distance between cities is less than 100 miles. Both persistence and volatility take values below the averages of all city pairs. In contrast, when we pick 76 city pairs in which the distance between cities is more than 2,000 miles, the averages of the persistence and volatility are above the averages of all city pairs. The contrast of these nearby and distant city pairings suggests that the persistence and volatility of LOP deviations are positively correlated to the distance separating the cities. In the next sub-section, we formally examine this relationship by regression analysis.

\subsection{Regression results}

The existing literature has assigned an important role for trade costs in the determination of LOP volatility. Specifically, Engel and Rogers (1996), Parsley and Wei (1996, 2001), among many others, have found that the LOP volatility is positively associated with the distance separating city pairs, a proxy for the trade cost. The well-known volatility-distance correlation is also confirmed in our dataset. When we pool all goods and run the volatilitydistance regression using two volatility measures reported in Table 1 with good-specific dummies, the coefficients on the logarithm of distance are found to be positive and significant. The magnitudes of estimated coefficients are broadly in line with Parsley and Wei (1996). ${ }^{4}$

Our main focus is the persistence-distance relationship, rather than the volatility-distance relationship. Thus, we use regression with its regressand replaced by persistence.

\footnotetext{
${ }^{4}$ In particular, the coefficient estimates are 0.008 with the standard errors (clustered by city pairs) of 0.0004 when the dependent variable is $s d_{q}$ and 0.03 with the standard errors of 0.002 when the dependent variable is $\operatorname{mapd}_{q}$.
} 


$$
\rho_{q_{j, k}}(i)=a(i)+b \ln d i s t_{j, k}+u_{j, k}(i),
$$

\section{[Locate Table 2 about here.]}

Specification (2) in Table 2 replaces the good-specific effects with the distribution cost shares used in Crucini and Shintani (2008) who find that goods with higher distribution cost shares exhibit higher LOP persistence. ${ }^{6}$ The distribution share is the wedge between what final consumers pay and what producers receive. These distribution costs include retail costs, markups and taxes. The distribution share can be used as an alternative measure of nontradability and, in fact, is included in the trade cost measures reported in Anderson and van Wincoop (2004). Our distribution shares are constructed based on sectoral US data aggregated to the national level. Therefore, our distribution shares vary across items but

\footnotetext{
${ }^{5}$ We also confirmed that the coefficients on distance were statistically significant based on standard errors clustered by goods.

${ }^{6}$ We compare the items from EIU's Worldwide Cost of Living Survey used in Crucini and Shintani (2008) with those from ACCRA dataset and construct the distribution share variable for our regression analysis.
} 
not across city pairs. Since the distance and distribution share are orthogonal to each other by construction, the coefficient on distance is essentially unaltered from specification (1). Consistent with the previous finding, the estimated coefficients on the distribution share 4 are all positive and significant. The estimates indicate that the goods and services with 5 higher distribution shares have a significantly slower speed of adjustment. The estimated coefficients range between 0.26 and 0.34 , depending on what regressand is used. This additional regression confirms a positive relationship between trade cost and persistence when trade costs are proxied either by the distance which captures city-pair variation or by the distribution share which captures good-specific variation.

In specifications (3) and (4), we perform the robustness analysis by including the degree of price stickiness in the regressions. These specifications are in the spirit of earlier studies emphasizing the effect of price stickiness on persistence of good-level real exchange rates or LOP deviations (e.g., Kehoe and Midrigan 2007, Crucini et al., 2010b, and Carvalho and Nechio 2011). These studies show theoretically (and confirm empirically) that LOP persistence is rising in the degree of price stickiness. Here, we measure the good-level degree of price stickiness $\lambda_{i}$ as the probability of no price change at a quarterly frequency measured by $\left(1-f_{i}\right)^{3}$, where $f_{i}$ is the monthly frequency of price changes reported by Nakamura and Steinsson (2008). Again, in both specifications, the coefficient on distance is essentially unaltered from specification (1). The coefficients on the distribution share in specification (4) decrease somewhat, but remain positive and statistically significant. We also note that the coefficient on $\lambda_{i}$ is positive which is consistent with theoretical prediction.

Our findings on the relationship between persistence and distance are broadly consistent with the few existing previous works. For example, Parsley and Wei (1996) report positive coefficients on the interaction terms of lagged relative prices and distance in augmented Dickey-Fuller regressions of relative prices between pairs of US cities. Their results imply that the convergence rate, measured by the SAR, is slower between cities that are further 
apart. Obstfeld and Taylor (1997) use disaggregated CPI data from 32 countries and US and Canadian cities and estimate a threshold autoregressive model with the price difference following a random walk within the band of arbitrage but converging to the level of trade cost from outside the band. They regress the estimated threshold on distance and find a weak positive relationship between persistence and distance because observed persistence typically becomes higher when the band of inaction widens. Cecchetti et al. (2002) examine the persistence of deviations from purchasing power parity (rather than LOP) using aggregate price indexes of 19 US cities from 1918 to 1995, and find that both the SAR and half-lives are positively correlated with distance. Choi and Matsubara (2007) investigate sector-level price differences among Japanese cities from 1970 to 2002. They find that, for 22 out of 36 items, the estimated half-lives are positively correlated with distance. Although estimation results from previous works described above may not be directly comparable to ours due to the difference in data and methods, the positive relationship between persistence and distance has been gaining empirical support in the literature.

\section{Model}

In this section, we develop a model with imperfect information and investigate whether it can explain the observed positive correlation between persistence and distance, as well as the observed positive correlation between volatility and distance.

\subsection{A noisy information model}

We employ a flexible price version of CST that adds noisy information about aggregate nominal expenditure to explain the positive persistence-distance correlation. The economy consists of two cities 1 and 2 within the same country. The economy is populated by a single representative household and a continuum of firms. Trade is over a continuum of goods, which involves the iceberg transportation cost of $\tau$ per unit to carry their goods between 
the two cities. Under monopolistic competition, firms set prices to satisfy demand for a particular good in a particular city (i.e., pricing to market). The representative household chooses consumption and labor supply over an infinite horizon subject to a cash-in-advance (CIA) constraint. The unit of time is one quarter.

We consider three levels of constant-elasticity-of-substitution (CES) aggregation. The lowest level of aggregation is across brands $v$. Here, brands produced in city 1 are indexed $v \in[0,1]$ while those produced in city 2 are indexed $v \in(1,2]$. The CES index for the consumption of a particular good $i \in[0,1]$ sold in a particular city $j(=1,2)$ is given by $C_{j, t}(i)=\left[(1 / 2)^{1 / \xi} \int_{0}^{2} C_{j, t}(i, v)^{(\xi-1) / \xi} d v\right]^{\xi /(\xi-1)}$, where $\xi$ is the elasticity of substitution across varieties satisfying $\xi>1$ and $C_{j, t}(i, v)$ denotes consumption for brand $v$ of good $i$ consumed in city $j$. Aggregating across the two cities gives national consumption of good $i, C_{t}(i)=\left[(1 / 2)^{1 / \xi} \sum_{j=1}^{2} C_{j, t}(i)^{(\xi-1) / \xi}\right]^{\xi /(\xi-1)} \cdot$ Aggregating further across goods $i$ gives aggregate national consumption, $C_{t}=\left[\int_{0}^{1} C_{t}(i)^{(\xi-1) / \xi} d i\right]^{\xi /(\xi-1)}$. The correspondent CES price indices for (i) good $i$ in city $j$, (ii) good $i$ nationally, and (iii) aggregate national consumption are given by, $P_{j, t}(i)=\left[(1 / 2) \int_{0}^{2} P_{j, t}(i, v)^{1-\xi} d v\right]^{1 /(1-\xi)}, P_{t}(i)=\left[(1 / 2) \sum_{j=1}^{2} P_{j, t}(i)^{1-\xi}\right]^{1 /(1-\xi)}$, and $P_{t}=\left[\int_{0}^{1} P_{t}(i)^{1-\xi} d i\right]^{1 /(1-\xi)}$, respectively. ${ }^{7}$

Households in this economy trade complete state-contingent financial claims and choose consumption $\left(C_{t}\right)$ and labor supply $\left(L_{t}\right)$ over an infinite horizon subject to budget and CIA constraints. The household instantaneous utility is given by $\ln C_{t}-\chi L_{t}$, resulting in the intra-temporal first-order condition between consumption and labor: $W_{t} / P_{t}=\chi C_{t}$, where $W_{t}$ is the nominal wage rate. The CIA constraint is $\Theta_{t}=P_{t} C_{t}$ and thus the nominal wage rate is proportional to the nominal money demand (or equivalently aggregate nominal expenditure): $W_{t}=\chi \Theta_{t}$. In this paper, we assume that the logarithm of aggregate nominal

\footnotetext{
${ }^{7}$ One can also consider an alternative sequence of aggregations which interchanges the aggregation across cities $j$ and the aggregation across goods $i$. While this allows for the general price indexes at the city level, such a change in the sequence of aggregation does not affect results in this paper.
} 
expenditure $\left(\theta_{t}=\ln \Theta_{t}\right)$ follows a random walk process:

$$
\theta_{t}=\theta_{t-1}+\varepsilon_{t}^{\theta}, \quad \varepsilon_{t}^{\theta} \sim N\left(0, \sigma_{\theta}^{2}\right),
$$

where $\varepsilon_{t}^{\theta}$ is independently and identically distributed. The firms' technology is:

$$
Y_{t}(i, v)=Z_{t}(i, v)\left[\Gamma_{t}^{d}(i, v)\right]^{\alpha}\left[L_{t}^{d}(i, v)\right]^{1-\alpha},
$$

where $Y_{t}(i, v), Z_{t}(i, v), \Gamma_{t}^{d}(i, v)$, and $L_{t}^{d}(i, v)$ denote output, exogenous productivity, the inputs of composite intermediate goods, and labor, respectively. Here $\alpha \in[0,1)$ is the share of intermediate goods and represents the degree of strategic complementarities (see Huang et al., 2004).

5 Note that the intermediate goods purchased by each firm are composites of all goods. ${ }_{6}$ Therefore, the market clearing condition for intermediate goods is given by $\int_{0}^{1} \int_{0}^{2} \Gamma_{t}^{d}(i, v) d v d i=$ ${ }_{7} \Gamma_{t}$ where $\Gamma_{t}$ is aggregate intermediate goods defined similarly to $C_{t}$ with the brand-level intermediate goods sold in city $j$, denoted as $\Gamma_{j, t}(i, v)$. Since firms must pay the iceberg transportation cost $\tau(>0)$ to carry their goods between cities, the market clearing conditions for each brand of each good satisfy

$$
\begin{aligned}
& Y_{t}(i, v)=C_{1, t}(i, v)+\Gamma_{1, t}(i, v)+(1+\tau)\left[C_{2, t}(i, v)+\Gamma_{2, t}(i, v)\right] \text { for } v \in[0,1], \\
& Y_{t}(i, v)=(1+\tau)\left[C_{1, t}(i, v)+\Gamma_{1, t}(i, v)\right]+C_{2, t}(i, v)+\Gamma_{2, t}(i, v) \text { for } v \in(1,2] .
\end{aligned}
$$

11 The market clearing condition for labor is given by $\int_{0}^{1} \int_{0}^{2} L_{t}^{d}(i, v) d v d i=L_{t}$.

We assume that productivity $\left(z_{t}(i, v)=\ln Z_{t}(i, v)\right)$ is common across brands, but specific to the good and the place of production:

$$
z_{t}(i, v)= \begin{cases}z_{1, t}(i) & \text { for } v \in[0,1] \\ z_{2, t}(i) & \text { for } v \in(1,2]\end{cases}
$$


where $z_{\ell, t}(i)$ follows a stationary ARMA process:

$$
A_{\ell}^{i}(L) z_{\ell, t}(i)=B_{\ell}^{i}(L) \varepsilon_{\ell, t}^{z}(i), \quad \varepsilon_{\ell, t}^{z}(i) \sim N\left(0, \sigma_{z}^{2}(\ell)\right)
$$

where $A_{\ell}^{i}(L)$ and $B_{\ell}^{i}(L)$ are lag polynomials for AR and MA components which differ across goods and the place of production. We further assume that $\sigma_{z}^{2}(\ell)$ is location specific such that the productivity innovations for good $i$ are independently drawn from a distribution with a location-specific variance. Using these assumptions, we allow for the possibility that persistence and volatility of $z_{\ell, t}(i)$ are both good- and location-specific. Throughout this paper, we measure the persistence of $z_{\ell, t}(i)$ by the first-order autocorrelation $\rho_{z, \ell}(i)$ and assume that $0<\rho_{z, \ell}(i)<1$ for $i \in[0,1]$ and $\ell=1,2$.

Following Angeletos and La'O (2009), we assume that each period is divided in two stages: In stage 1, prices are set under imperfect information; In stage 2, the information on $\theta_{t}$ is revealed, and consumption and employment choices are made taking the prices predetermined in stage 1 as given. Building on the framework of Angeletos and La'O (2009), we introduce retail managers who decide prices for each firm. Managers set prices for the firm's brands in the city in which they live. The retail managers are assumed to be fully informed about the productivity of their own firm, but imperfectly informed about the current state of nominal aggregate demand.

In stage 1 , retail managers receive idiosyncratic noisy signals $x_{j, t}(i, v)$ of $\theta_{t}$ :

$$
x_{j, t}(i, v)=\theta_{t}+\varepsilon_{j, t}^{x}(i, v), \quad \text { where } \varepsilon_{j, t}^{x}(i, v) \sim N\left(0, \sigma_{x}^{2}(j)\right)
$$

We allow retail managers' signals and variability of noise $\varepsilon_{j, t}^{x}(i, v)$ to differ across cities $j$. Recall that $\sigma_{z}^{2}(\ell)$ is location specific. We also assume that $\sigma_{x}^{2}(j)$ is location specific such that $\varepsilon_{j, t}^{x}(i, v)$ is independently drawn from a distribution with a location-specific variance. This reflects the assumption that retail managers are isolated in city $j$ in terms of their 
information and receive idiosyncratic signals of nominal aggregate demand with different levels of precision.

Following Angeletos and La'O (2009), in stage 2, aggregate nominal expenditure becomes common knowledge (see also, Fukunaga, 2007). We later discuss the possibility of replacing this assumption with an alternative of persistent informational deficiencies. Let $\mathbb{I}_{j, t}(i, v)$ and $\mathbb{I}_{j, t}^{\prime}(i, v)$ be the information sets in period $t$, for the retail managers in city $j$ at stages 1 and 2 , respectively. Within period $t$, the retail managers' information set evolves as follows:

$$
\mathbb{I}_{j, t}(i, v)=\mathbb{I}_{j, t-1}^{\prime}(i, v) \cup\left[x_{j, t}(i, v), z_{t}(i, v)\right] \text { and } \mathbb{I}_{j, t}^{\prime}(i, v)=\mathbb{I}_{j, t}(i, v) \cup\left\{\theta_{t}\right\}
$$

3 Note that the information is purely idiosyncratic: the information set differs across $j, i$, and $4 v$.

The log-linearization of the optimal individual prices, with suppressed constant terms, yields

$$
p_{j, t}(i, v)=(1-\alpha) \mathbb{E}_{j, t}\left(\theta_{t} \mid i, v\right)+\alpha \mathbb{E}_{j, t}\left(p_{t} \mid i, v\right)-z_{t}(i, v)
$$

${ }_{5}$ where $p_{j, t}(i, v)=\ln P_{j, t}(i, v), p_{t}=\ln P_{t}$, and $\mathbb{E}_{j, t}(\cdot \mid i, v)$ denotes the expectation operator ${ }_{6}$ conditional on $\mathbb{I}_{j, t}(i, v){ }^{8}$ Note that $\theta_{t}$ appears in $(9)$ because the nominal wage rate in our 7 model is proportional to the aggregate nominal expenditure.

The price index for good $i$ sold in city 1 can be approximated by

$$
p_{1, t}(i)=s \int_{0}^{1} p_{1, t}(i, v) d v+(1-s) \int_{1}^{2} p_{1, t}(i, v) d v
$$

where $s$ is the steady state expenditure share on home-produced goods, or the "home bias"

\footnotetext{
${ }^{8}$ See Appendix A.1 for the derivation of (9). In general, the optimal prices differ across the locations of sales because of the presence of the trade cost. However, since we suppressed the constant term which depends on the trade cost, (9) can be used for both cases of $j=k$ and $j \neq k$.
} 
parameter satisfying $s>1 / 2$. This home bias parameter $s$ is given by

$$
s=\frac{1}{1+(1+\tau)^{1-\xi}} .
$$

Importantly, $s$ is an increasing function of $\tau$. The home bias makes the home city price 2 index more sensitive to the price of home-produced goods than that of goods produced in 3 the other city. Since a larger home bias is caused by more costly transportation of goods, $s$ 4 is increasing in $\tau$. The price in city $2, p_{2, t}(i)$, is similarly derived.

Finally, we address how expectations about nominal aggregate demand are formed. We use a standard signal extraction problem:

$$
\mathbb{E}_{j, t}\left(\theta_{t} \mid i, v\right)=\kappa_{j} x_{j, t}(i, v)+\left(1-\kappa_{j}\right) \theta_{t-1} \text { for } j=1,2,
$$

${ }_{5}$ where $\kappa_{j}$ is the steady-state Kalman gain defined as $\sigma_{\theta}^{2} /\left[\sigma_{\theta}^{2}+\sigma_{x}^{2}(j)\right]$.

\subsection{Characterizing the equilibrium}

$7 \quad$ The model is solved by the method of undetermined coefficients. The resulting equilib8 rium prices are characterized by the following proposition:

Proposition 1 Under the preference assumption $(\ln C-\chi L)$, the CIA constraint, the stochastic processes of aggregate nominal expenditure (1) and productivity (6), and the imperfect information specified as (7) and (8), the aggregate price index is given by

$$
p_{t}=\omega \theta_{t}+(1-\omega) \theta_{t-1},
$$

9 where $\omega=(1-\alpha) \bar{\kappa} /(1-\alpha \bar{\kappa})$ and $\bar{\kappa}=\left(\kappa_{1}+\kappa_{2}\right) / 2$. The price indexes for good $i$ sold in 
1 city 1 and 2 can be expressed as

$$
\begin{aligned}
& p_{1, t}(i)=(1-\alpha+\alpha \omega) \kappa_{1} \varepsilon_{t}^{\theta}+\theta_{t-1}-s z_{1, t}(i)-(1-s) z_{2, t}(i) \\
& p_{2, t}(i)=(1-\alpha+\alpha \omega) \kappa_{2} \varepsilon_{t}^{\theta}+\theta_{t-1}-s z_{2, t}(i)-(1-s) z_{1, t}(i)
\end{aligned}
$$

respectively. Also, the relative price $q_{t}(i) \equiv p_{2, t}(i)-p_{1, t}(i)$ equals

$$
q_{t}(i)=\phi \varepsilon_{t}^{\theta}+(2 s-1) z_{t}(i)
$$

where $\phi=(1-\alpha) \kappa /(1-\alpha \bar{\kappa}), \kappa=\kappa_{2}-\kappa_{1}$, and $z_{t}(i)=z_{1, t}(i)-z_{2, t}(i)$.

The proof is provided in Appendix A.2. Here $\bar{\kappa}$ may be interpreted as the level of information precision in the macroeconomy and $\kappa$ is a measure of the spatial dispersion of information precision between the two cities. For ease of exposition, $\kappa$ is referred to as the information difference, which is one of the key parameters of the model. Without loss of generality, let $\kappa_{1} \leq \kappa_{2}$ so that $\kappa \geq 0$. Finally, $z_{t}(i)$ represents the productivity difference between two cities.

Equations (13) and (14) indicate that $p_{j, t}(i)$ is affected by $\varepsilon_{t}^{\theta}, z_{1, t}(i)$, and $z_{2, t}(i)$. Here, the response of $p_{j, t}(i)$ to $\varepsilon_{t}^{\theta}$ varies across cities, depending on the precision of signals that managers receive in each city. If managers in city $j$ have less precise signals (larger $\sigma_{x}^{2}(j)$ ), individual prices in city $j$ respond less to signals (smaller $\kappa_{j}$ ) and thus $p_{j, t}(i)$ is less sensitive to shocks to aggregate nominal expenditure. Also, $p_{j, t}(i)$ responds to productivity shock in the home city more strongly than in the other city, due to the home bias in expenditure shares arising from trade costs (i.e., $s>1 / 2$ ).

Difference in price responses between (13) and (14) generates the LOP deviations in (15). It should be noted that $q_{t}(i)$ now only depends on $\varepsilon_{t}^{\theta}$ and $z_{t}(i)$. First, the aggregate nominal demand shock $\varepsilon_{t}^{\theta}$ matters for $q_{t}(i)$. To see this, suppose productivity is equal across cities so that $z_{t}(i)=0$. The difference in price responses to $\varepsilon_{t}^{\theta}$ gives rise to an LOP 
1 deviation that lasts for one period because $\varepsilon_{t}^{\theta}$ is assumed to be fully revealed to all managers in the next period. ${ }^{9}$ The coefficient $\phi$ on $\varepsilon_{t}^{\theta}$ is increasing in the information differences. Second, the productivity difference between two cities $z_{t}(i)$ also drives LOP deviations. ${ }^{10}$ ${ }_{4}$ To understand how $z_{t}(i)$ affects LOP deviations, suppose that $\varepsilon_{t}^{\theta}=0$ and that productivity 5 in city 1 increases by one percent. The difference in price responses to $z_{1, t}(i)$ leads to an

${ }^{9} \mathrm{~A}$ more general treatment would allow for the presence of persistent informational deficiencies. As in the case of Mankiw and Reis (2002) and Woodford (2003), the nominal shocks will have a longer effect.

${ }^{10}$ Note that $q_{t}(i)$ in $(15)$ can always be approximated by the $\operatorname{AR}(p)$ process with a large $p$. This justifies the use of the $\operatorname{AR}(p)$ model in computing the persistence measures in Section 2. For example, when $z_{1, t}(i)$ and $z_{2, t}(i)$ follow an $\operatorname{AR}(1)$ process with common persistence parameter $\rho_{z}(i), q_{t}(i)$ can be expressed as an $\operatorname{ARMA}(1,1)$ process, which has an $\operatorname{AR}(\infty)$ representation.

${ }^{11}$ It is straightforward to show that the LOP persistence remains invariant to the trade cost, even when sticky prices are introduced into the model. 


\subsection{Comparative statics} of $z_{t}(i)$ is simply the sum of variances of the location-specific productivity (i.e., $\operatorname{var}\left[z_{t}(i)\right]=$ $\left.\operatorname{var}\left[z_{1, t}(i)\right]+\operatorname{var}\left[z_{2, t}(i)\right]\right)$. Consequently, the first-order autocorrelation of $z_{t}(i)$ can be expressed as a weighted average of the first-order autocorrelations of $z_{1, t}(i)$ and $z_{2, t}(i)$ :

$$
\rho_{z}(i)=\frac{\operatorname{var}\left[z_{1, t}(i)\right]}{\operatorname{var}\left[z_{t}(i)\right]} \rho_{z, 1}(i)+\frac{\operatorname{var}\left[z_{2, t}(i)\right]}{\operatorname{var}\left[z_{t}(i)\right]} \rho_{z, 2}(i)
$$

Using (15), the standard deviation of the LOP deviation is $s d_{q}(i)=\sqrt{\operatorname{var}\left[q_{t}(i)\right]}$ where

$$
\operatorname{var}\left[q_{t}(i)\right]=\phi^{2} \sigma_{\theta}^{2}+(2 s-1)^{2} \operatorname{var}\left[z_{t}(i)\right]
$$


1 the extent of the information differences across retail managers. ${ }^{12}$ We summarize the main 2 results of our paper in the the following proposition .

Proposition 2 Under the maintained assumptions in Proposition 1, LOP deviations have the following properties:

(i) volatility measured by $s d_{q}(i)$ is increasing in the trade cost $\tau, \partial s d_{q}(i) / \partial \tau>0$;

(ii) persistence measured by $\rho_{q}(i)$ is independent of the trade cost $\tau$ when information about nominal aggregate demand, $\theta_{t}$, is perfect (i.e., $\sigma_{x}(1) \rightarrow 0$ and $\sigma_{x}(2) \rightarrow 0$ ) or when information on $\theta_{t}$ is imperfect and information difference between managers in different cities is absent (i.e., $\kappa=0), \partial \rho_{q}(i) / \partial \tau=0$;

(iii) persistence measured by $\rho_{q}(i)$ is increasing in the trade cost $\tau$ when information about $\theta_{t}$ is imperfect and information difference between managers in different cities is present (i.e., $\kappa \neq 0), \partial \rho_{q}(i) / \partial \tau>0$

The proposition implies that, when trade costs rise with the distance separating locations, the model with perfect information can account for the positive volatility-distance correlation discovered by the literature, but fails to predict the positive persistence-distance correlation. In contrast, the presence of an information difference across managers in different cities can account for both observations. ${ }^{13}$

To see the intuition for part (i) of Proposition 2, again suppose that there is a one percent increase in the location-specific productivity of city 1 . If the trade cost is absent, the steady state expenditure share $s$ equals $1 / 2$, which implies that price indexes in both cities fall by the same amount and the relative price, $q_{t}(i)=p_{2, t}(i)-p_{1, t}(i)$, remains unchanged. In contrast, the presence of the trade cost causes home bias and the price index in city 1 falls

\footnotetext{
${ }^{12}$ Appendix A.3 provides the derivations of (16) - (18).

${ }^{13}$ As pointed out by an anonymous referee, Proposition 2 holds even if the assumption of heterogeneous information across retail managers given by (7) is replaced by the assumption of homogeneous information given by $x_{j, t}(i, v)=x_{j, t}=\theta_{t}+\sigma_{x}^{2}(j) \varepsilon_{t}^{x}$, where $\varepsilon_{t}^{x} \sim N(0,1)$. However, in such a case, dynamics of $q_{t}(i)$ will become more complicated and cannot be described simply by (15).
} 
more than that in city 2. Higher trade costs amplify this expenditure asymmetry which causes higher volatility of relative prices.

Let us now turn to part (ii) of Proposition 2. With perfect information, the effect of a change in $\theta_{t}$ on the price indexes in two cities cancels out because managers increase prices by the same amount in two cities. The same intuition applies to the case of the imperfect information without information difference. Because the same information precision of uninformed managers implies price increases by the same amount, in response to an increase in $\theta_{t}$, the effect on the price indexes cancels out. In either of these cases, the relative prices are solely determined by the productivity differences and the persistence of $q_{t}(i)$ corresponds to the persistence of $z_{t}(i)$ which is independent of the trade cost.

The result of part (iii) of Proposition 2 can be explained as follows. When imperfect information is present with asymmetric information precision across managers in different cities, LOP deviations with imperfect information consist of two components: the i.i.d. process $\phi \varepsilon_{t}^{\theta}$ and the persistent process of $(2 s-1) z_{t}(i)$. Consequently, the persistence of LOP deviations is determined by the weighted average of the persistence of the two components. Thus, the persistence of $q_{t}(i)$ is bounded between zero and $\rho_{z}(i)$ and, in fact, the coefficient on $\rho_{z}(i)$ in (18) is the weight for the productivity difference. In the trivial case in which the home bias is zero $(s \rightarrow 1 / 2)$, the LOP deviations are determined solely by i.i.d. innovations to aggregate nominal expenditure. As trade costs become larger, home bias increases $(s>1 / 2)$ and the contribution of the productivity difference to persistence rises. Therefore, when the trade cost is high, LOP deviations become more persistent. Indeed, the persistence of LOP rises from zero toward $\rho_{z}(i)$ as the trade cost increases.

Two additional remarks are useful at this point. First, it is of interest to see if the results in Proposition 2 continue to hold when Angeletos and La'O's (2009) assumption of shortlived informational deficiencies is replaced by more persistent informational deficiencies, as in Mankiw and Reis (2002) and Woodford (2003). As long as informational deficiencies are less 
1 persistent than the productivity difference, our results remain valid. If $\bar{\kappa}$ is relatively large 2 or $\alpha$ is relatively small, this condition is likely to be met under typical speed of informational deficiency adjustment considered in the modern imperfect information literature. Second, ${ }_{4} z_{t}(i)$ disappears from $(15)$ if the productivity $z_{\ell, t}(i)$ is common across two cities. Even when ${ }_{5} z_{t}(i)$ is absent, if the model has city-specific preference shocks biased toward home goods 6 and if the preference shocks in the two cities are persistent, the same qualitative results as 7 in Proposition 2 can be obtained. ${ }^{14}$ In this sense, our results do not critically depend on the assumption of the location-specific productivity.

\subsection{Numerical examples}

So far, persistence of $q_{t}(i)$ was demonstrated to be positively associated with trade costs in the noisy information model. At the same time, (18) shows that three key parameters $\left(\kappa, \alpha, \rho_{z}(i)\right)$ determine the level of LOP persistence that arises in equilibrium. Here, we provide some assessment of the empirical relevance of the theory. We first ask how $\rho_{q}(i)$ changes over a plausible range of trade cost in the model. In particular, we show how $\rho_{q}(i)$ changes as a function of $\tau$ for various settings of $\kappa, \alpha$, and $\rho_{z}(i)$, keeping the other parameters $\bar{\kappa}, \xi$, and $\operatorname{var}\left[z_{t}(i)\right] / \sigma_{\theta}^{2}$ constant. We then evaluate the model based on its ability to replicate the estimated coefficient on distance in our persistence-distance regressions.

Beginning with the parameters whose values are kept constant throughout our analysis, the average of the Kalman gains across managers is set to $\bar{\kappa}=0.5$, the benchmark value employed by Angeletos and La'O (2009) in their simulations. Conveniently, this makes $\kappa$ lie on the unit interval $[0,1]$. The one extreme is $\kappa=0$, where the noise-to-signal ratio is common across managers: $\sigma_{x}^{2}(1) / \sigma_{\theta}^{2}=\sigma_{x}^{2}(2) / \sigma_{\theta}^{2}=1$. The other extreme is $\kappa=1.00$, where one manager has no information about the shocks to $\theta_{t}$ while the other receives a perfect signal: $\sigma_{x}^{2}(1) / \sigma_{\theta}^{2}=\infty$ and $\sigma_{x}^{2}(2) / \sigma_{\theta}^{2}=0$. The elasticity of substitution across goods is set to $\xi=4$, a value taken from Broda and Weinstein (2006). Note that (18) implies that the

\footnotetext{
${ }^{14}$ Details of this result is provided in Appendix A.4.
} 
1 persistence depends on the variance ratio, $\operatorname{var}\left[z_{t}(i)\right] / \sigma_{\theta}^{2}$. We follow Crucini et al. (2013) and set $\sqrt{\operatorname{var}\left[z_{t}(i)\right] / \sigma_{\theta}^{2}}=5 .^{15}$

Grossman (1998) and Hummels (2001), among others, specify the relationship between trade costs and distance as a power function

$$
\tau=c \times d i s t^{\delta}
$$

\footnotetext{
${ }^{15}$ One of benchmark values of the standard deviation ratio of real shock to nominal shock was 5 in their analysis of international LOP. They claim that the value of 5 matches well with their data, compared to alternative values of 1 and $1 / 5$.

${ }^{16}$ Based on the US data, Anderson and van Wincoop (2004) estimate that total international frictions average 74 percent. These frictions are further divided into those arising from transportation costs amounting to a wedge of 0.21 percent and a border-related wedge of 0.44 percent $(0.74=1.21 \times 1.44-1)$. Due to the absence of the international border in our model, our choice of $\bar{\tau}=0.20$ seems reasonable for an average across bilateral city pairs.
} 
1 panel of the figure shows that, regardless of values of information difference, the volatility of LOP deviations depends positively on $\ln \tau \cdot{ }^{17}$ In contrast, the curves for persistence in the left panel are upward-sloping only when $\kappa$ is non-zero. If $\kappa=0$, the persistence curve is flat, independent of $\ln \tau$ and equal to $\rho_{z}(i)(=0.60)$. An increase in $\kappa$ can be interpreted as a larger information difference between cities, and thus $\phi$, ceteris paribus, increases. The increase in $\phi$ leads to a decline in the persistence of the LOP deviation because a larger information difference increases the importance of the i.i.d. nominal demand shock relative to the persistent productivity difference in the determination of the LOP deviations.

\section{[Locate Figure 1 about here.]}

Figure 2 shows persistence and volatility and their sensitivity to $\alpha$, when the other two key parameters are fixed at $\kappa=0.50$ and $\rho_{z}(i)=0.60$. In Woodford's (2003) model of monetary non-neutrality where prices fluctuate according to shocks to aggregate nominal expenditure, he has emphasized that strategic complementarities can generate substantial persistence in output dynamics. We show that strategic complementarities also affect both the persistence and volatility of relative prices across locations. Stronger strategic complementarities raise the persistence because price indexes are more persistent, through smaller $\phi$. However, smaller $\phi$ also dampens the volatility, since the effect of $\varepsilon_{t}^{\theta}$ on $q_{t}(i)$ is weakened.

\section{[Locate Figure 2 about here.]}

Finally, Figure 3 shows persistence and volatility and their sensitivity to $\rho_{z}(i)$, when other two key parameters are set at $\alpha=0$ and $\kappa=0.50$. Not surprisingly, the left panel of the figure shows the higher $\rho_{z}(i)$ corresponds to the higher $\rho_{q}(i)$ since the latter is proportional to the former (see (18)). In contrast, the volatility of LOP deviations is the same for all $\rho_{z}(i)$ simply because $\operatorname{var}\left[z_{t}(i)\right]$ and $\sigma_{\theta}^{2}$ in (17) remain unchanged by changing $\rho_{z}(i)$.

\footnotetext{
${ }^{17}$ The volatility curve is drawn by fixing $\sigma_{\theta}^{2}$ at 0.01 along with the assumption of $\sqrt{\operatorname{var}\left[z_{t}(i)\right] / \sigma_{\theta}^{2}}=5$.
} 


\section{[Locate Figure 3 about here.]}

While these figures are helpful in understanding the mechanism, we further investigate whether our model can reproduce the estimated coefficient on distance in our regression analysis. To answer this question, we calibrate the regression coefficient from the model based on the following procedure.

Note that our analysis in Section 2 employs a linear regression of LOP persistence on distance, whereas the first-order autocorrelation in (18) is non-linear in trade cost. We first linearly approximate (18) around $\ln \bar{\tau}$, and then use (19) to transform the coefficient on trade cost to that on distance. This predicted coefficient on distance corresponds to the slope of persistence curve in Figures $1-3$ evaluated at $\ln 0.20(\approx-1.61)$ multiplied by $\delta=0.30$. While the slope depends on all the key parameters, $\kappa, \alpha$, and $\rho_{z}(i)$, we pay special attention to $\kappa$ because the presence of information difference is the essential feature in producing the persistence-distance correlation in the noisy information model.

Panel A of Table 3 reports the coefficients on distance for various $\kappa$, using the baseline model for the purpose of matching the estimated coefficient of 0.02 in Table 2. Note that the standard errors reported in Table 2 imply that the 95 percent confidence interval of the estimated coefficient is given by $[0.016,0.024]$. This provides lower and upper bounds for $\kappa$, which are reported in the last two columns of the table. The first three rows in the panel show the predicted coefficients for different levels of strategic complementarity, $\alpha=0.90$ 0.45 , and 0 , with $\rho_{z}(i)$ fixed at 0.60 . When strategic complementarities are strong, such as $\alpha=0.90$, increasing the informational asymmetry has little effect on the slope coefficient, resulting in the failure of the model to replicate the persistence-distance relation in the data. However, for smaller values of $\alpha$, the model performs well over a reasonable range of $\kappa$. For example, the predicted range of $\kappa$ is $[0.45,0.57]$ when $\alpha=0.45$, while the predicted range is $[0.32,0.41]$ when $\alpha=0$. Thus, the information difference required for replicating the estimated coefficient becomes smaller, as the degree of strategic complementarities becomes 
lower.

2

3

4

5

\section{[Locate Table 3 about here.]}

Next two rows show the effects of changing $\rho_{z}(i)$, while keeping $\alpha=0$. When $\rho_{z}(i)=$ 0.30 , the required level of $\kappa$ increases compared to the benchmark case of $\rho_{z}(i)=0.60$. In contrast, when $\rho_{z}(i)=0.90$, the required level of $\kappa$ decreases. This simply reflects the fact that the change of $\rho_{z}(i)$ has a proportional effect on the slope of $\rho_{q}(i)$ and the predicted coefficient. At the same time, the range of $\kappa$ that is consistent with the data becomes wider as $\rho_{z}(i)$ becomes smaller.

\section{Discussion}

In this section, we discuss the robustness of our results to the case of sticky prices or multiple cities.

\subsection{The role of price stickiness}

The baseline model assumes that prices of all goods are completely flexible. Empirical studies on micro price data, however, have discovered substantial heterogeneity in the degree of price stickiness across goods. In Section 2, we found that, even after controlling for the distribution share, LOP persistence was higher for goods whose prices changed less frequently. To take this feature into account, we follow Kehoe and Midrigan (2007) and CST in assuming that the degree of price stickiness differs across goods but is common across locations. Each period, retail managers can reset their price with a constant probability $1-\lambda_{i}$. To simplify the argument, let us assume $\alpha=0$ and that $z_{1, t}(i)$ and $z_{2, t}(i)$ follow a common $\operatorname{AR}(1)$ process (i.e., $\rho_{z, 1}(i)=\rho_{z, 2}(i)=\rho_{z}(i)$ and $\left.\sigma_{z}(1)=\sigma_{z}(2)\right)$.

The LOP deviation from the noisy information model with sticky prices follows the first- 
order difference equation:

$$
q_{t}(i)=\lambda_{i} q_{t-1}(i)+\left(1-\lambda_{i}\right)\left[\kappa \varepsilon_{t}^{\theta}+\frac{1-\lambda_{i} \beta}{1-\lambda_{i} \beta \rho_{z}(i)}(2 s-1) z_{t}(i)\right]
$$

where $\beta$ is the discount factor satisfying $\beta \in(0,1) .{ }^{18}$

This can be compared to our flexible price model by setting $\lambda_{i}=0$, to arrive at $q_{t}(i)=$ $\kappa \varepsilon_{t}^{\theta}+(2 s-1) z_{t}(i)$. The only difference between this equation and (15) is the absence of strategic complementarity $(\alpha=0)$, in which case $\phi=\kappa$. As $\lambda_{i}$ increases, prices respond less to signals about nominal aggregate demand (i.e., demand channel) or to productivity (i.e., productivity channel). Thus, the persistence is rising and the volatility is falling in $\lambda_{i}$.

Proposition 2 continues to hold for (20) because the coefficient on $z_{t}(i)$ is still increasing in $\tau$, due to the presence of $(2 s-1)$ as in (15). Price stickiness mitigates the productivity channel even further than the demand channel through the coefficient $\left(1-\lambda_{i} \beta\right) /\left[1-\lambda_{i} \beta \rho_{z}(i)\right](<1)$. While the quantitative implications become slightly different because of this coefficient, the higher trade cost still gives rise to more persistent $q_{t}(i)$ through larger home bias.

We investigate whether the model with sticky prices can quantitatively account for the regression results. The simple average of the degree of price stickiness across good used in our regression analysis is 0.65 . This value implies that prices remain fixed for 8.6 months on average, consistent with the findings of Nakamura and Steinsson (2008) who estimate the median duration of regular prices is 8 - 11 months. To account for substantial heterogeneity in the degree of price stickiness across goods, the cases of $\lambda_{i}=0.35$ and 0.95 are contrasted. Panel B of Table 3 reports the predicted regression slope from the model with sticky prices when $\alpha=0$ and $\rho_{z}(i)=0.60$. Other parameter values are same as the case of the baseline flexible price model. The results show that the model can replicate the estimated coefficient when $\lambda_{i}$ is either 0.35 and 0.65 . The range of $\kappa$ consistent with the data becomes wider with sticky prices compared to the baseline flexible price model. However, when $\lambda_{i}$ becomes as

\footnotetext{
${ }^{18}$ Derivation of this equation is provided in Appendix A.5.
} 
1 large as 0.95 , the model fails to replicate the observed regression slope.

\subsection{Multi-city model}

The baseline framework is a two-city model, whereas the data span numerous cities. This section considers an $N$ city extension of the model. Beginning with the price index in a representative city (e.g., city 1), we have

$$
P_{1, t}(i)=\left[\frac{1}{N} \int_{0}^{N} P_{1, t}(i, v)^{1-\xi} d v\right]^{\frac{1}{1-\xi}}
$$

We derive the explicit solution for LOP deviations in the multi-city model where the trade cost can differ across city pairs. ${ }^{19}$ In this multi-city model, we redefine the LOP deviations between cities 1 and 2 as $q_{2,1, t}(i)=\ln \left[P_{2, t}(i) / P_{1, t}(i)\right]$. We also denote $\tau_{\ell, j}$ by the iceberg transportation cost to carry goods from city $\ell$ to $j$, where $\tau_{\ell, j}$ satisfies the assumptions that $\tau_{\ell, j}=\tau_{j, \ell}$ and $\tau_{j, j}=0$. Under flexible prices, $q_{2,1, t}(i)$ is given by

$$
q_{2,1, t}(i)=\phi_{2,1} \varepsilon_{t}^{\theta}+\sum_{\ell=1}^{N}\left(s_{\ell, 1}-s_{\ell, 2}\right) z_{\ell, t}(i)
$$

where

$$
s_{\ell, j}=\frac{\left(1+\tau_{\ell, j}\right)^{1-\xi}}{\sum_{m=1}^{N}\left(1+\tau_{m, j}\right)^{1-\xi}} \text { for } j=1,2 \text { and } \ell=1,2, \ldots, N
$$

and $\phi_{2,1}=(1-\alpha) \kappa_{2,1} /(1-\alpha \bar{\kappa}), \bar{\kappa}=N^{-1} \sum_{j=1}^{N} \kappa_{j}$ and $\kappa_{2,1}=\kappa_{2}-\kappa_{1}$. We note that $\bar{\kappa}$ is the average of information precision across all $N$ types of managers while $\kappa_{2,1}$ remains the spatial dispersion of information precision between two cities under examination. The parameter $s_{\ell, j}$ is the steady-state expenditure share of consumption in city $j$ on goods produced in city $\ell$. When $\ell=j$, this parameter can be understood as the home bias parameter as in the s two-city model. Also, when $N=2, s_{\ell, 1}-s_{\ell, 2}$ reduces to $2 s-1$ for $\ell=1$ and $1-2 s$ for $\ell=2$.

\footnotetext{
${ }^{19}$ Details of this derivation is provided in Appendix A.6.
} 
Hence, (22) generalizes (15) in the two-city model.

Compared to the two-city model, the LOP deviations still include both temporary and persistent components and the coefficient on $\varepsilon_{t}^{\theta}$ remains effectively unchanged. However, there is no longer the productivity difference in (22). Instead, the productivity for each city contributes to dynamics of LOP deviations even when the relative price between cities 1 and 2 is considered. This is because the prices in cities 1 and 2 include prices of brands produced in all cities in the economy, as indicated in (21).

Let us assume that all $z_{\ell, t}(i)$ have a common variance and first-order autocorrelation (i.e., $\rho_{z, 1}(i)=\rho_{z, 2}(i)=\cdots=\rho_{z, N}(i)$ and $\left.\operatorname{var}\left[z_{1, t}(i)\right]=\operatorname{var}\left[z_{2, t}(i)\right]=\cdots=\operatorname{var}\left[z_{N, t}(i)\right]\right)$. Then, the first-order autocorrelation of $q_{2,1, t}(i)$ is given by

$$
\rho_{q, 2,1}(i)=\frac{\psi^{2} \operatorname{var}\left[z_{1, t}(i)\right]}{\phi_{2,1}^{2} \sigma_{\theta}^{2}+\psi^{2} \operatorname{var}\left[z_{1, t}(i)\right]} \rho_{z, 1}(i),
$$

where $\psi^{2}=\sum_{\ell=1}^{N}\left(s_{\ell, 1}-s_{\ell, 2}\right)^{2}$. The underlying structure of the LOP persistence shown in (24) is similar to that under the two-city model. As long as $\psi$ is increasing in $\tau_{1,2}$, the model can still explain a positive persistence-distance correlation.

Unfortunately, we cannot determine the sign of the derivative of $\psi$ with respect to $\tau_{1,2}$ in general. Hence, the need for simulations. As in the previous exercise, we linearly approximate (24) around $\ln \bar{\tau}$ and use (19) for $\tau_{1,2}$ in evaluating the model. For comparison purpose, we report the case of $N=3, \alpha=0$ and $\rho_{z, 1}(i)=\rho_{z, 2}(i)=\rho_{z, 3}(i)=0.60$ to see the marginal changes in results. ${ }^{20}$

Panel $\mathrm{C}$ of Table 3 shows the coefficients on distance for the three-city model for various values of $\kappa$ (more precisely $\kappa_{2,1}$ ). In both rows of the panel, the partial derivative of $\rho_{q, 2,1}(i)$ with respect to the log distance is computed numerically. The first row of the panel assumes that the trade cost is the same across all three city pairs. Under this assumption, $\kappa$ required for replicating the estimated coefficient on distance is smaller than in the two-city model,

\footnotetext{
${ }^{20}$ For the variance ratio of real and nominal shocks, we set $\sqrt{3 \times \operatorname{var}\left[z_{1, t}(i)\right] / \sigma_{\theta}^{2}}=5$.
} 
while the range of $\kappa$ that is consistent with the data is narrower. The second row of the panel allows for different trade costs between cities 1 and 3 and between cities 2 and 3. Here, while $\tau_{1,2}$ remains unchanged at $0.20, \tau_{1,3}$ and $\tau_{2,3}$ are set to 0.30 and 0.10 , respectively, to keep the average trade cost unchanged at $\bar{\tau}=0.20 .^{21}$ Under this parameterization, the required level of $\kappa$ becomes slightly higher than the case of symmetric trade costs and the range of $\kappa$ is wider, but neither change is very substantial. Hence, our calibration results suggest that, within a reasonable range of parameter values, the three-city model continues to imply a positive persistence-distance correlation and can still explain the observed regression coefficient. Similar results can be obtained even if we combine the multi-city model with sticky prices, as shown in Panel D of Table 3 with the choice of $\lambda_{i}=0.65$. To sum up, the main predictions of the noisy information model are robust.

\section{Conclusion}

This paper studies micro price data across US cities to provide empirical evidence that persistence of intra-national LOP deviations is positively correlated with the distance between cities. To explain the empirical findings, we develop a model of time-varying productivity combined with imperfect information about nominal aggregate demand. Assuming that distance proxies trade cost between two cities, we found that the perfect information model can account for the observed positive volatility-distance correlation pointed out by the literature but fails to predict the observed positive persistence-distance correlation. In contrast, the noisy information model can account for both observations if there is an information difference across managers in different cities. The key mechanism is that shocks arising from imperfect information are temporary while shocks from productivity are longlived. When trade costs are low, the effect of the temporary nominal shock is strong relative to the effect of persistent real shocks on the persistence of LOP deviations. When the trade

\footnotetext{
${ }^{21}$ Note that these additional parameter values fall within the range of $\tau \in[0.07,0.30]$ in the data.
} 
costs are high, the former is weak relative to the latter and the persistence of LOP deviations approaches the persistence of technology shocks. Under the perfect information, this change in relative contribution between nominal and real shocks does not arise because nominal shocks do not contribute to persistence in LOP deviations.

Our findings suggest the importance of imperfect information for better understanding persistent and volatile LOP deviations, while not ruling out other plausible mechanisms. For example, productivity spill-overs across manufacturers may be negatively correlated with distance. This could produce a positive persistence-distance correlation in LOP deviations. However, careful investigation of this requires highly disaggregated data on productivity.

\section{References}

Anderson, J. E. and E. van Wincoop. 2004. "Trade costs." Journal of Economic Literature, $42(3), 691-751$.

Angeletos, G-M. and J. La'O. 2009. "Incomplete information, higher-order beliefs and price inertia." Journal of Monetary Economics, 56, S19-S37.

Broda, C. and D. E. Weinstein. 2006. "Globalization and the gains from variety." Quarterly Journal of Economics, 121 (1), 541-585.

Cecchetti S. G., N. C. Mark, and R. J. Sonora. 2002. "Price index convergence among United States cities." International Economic Review, 43 (4), 1081-1099.

Carvalho C. and F. Nechio. 2011. "Aggregation and the PPP puzzle in a sticky-price model." American Economic Review, 101 (6), 2391-2424.

Choi, C.-Y. and K. Matsubara. 2007. "Heterogeneity in the persistence of relative prices: what do the Japanese cities tell us?" Journal of the Japanese and International Economies, 21 (2), 260-286.

Crucini, M. J. and M. Shintani. 2008. "Persistence in law of one price deviations: Evidence from micro-data." Journal of Monetary Economics, 55 (3), 629-644. 
Crucini, M. J., M. Shintani, and T. Tsuruga. 2010a. "The law of one price without the $2 \quad$ border: The role of distance versus sticky prices." Economic Journal, 120, 462-480.

Crucini, M. J., M. Shintani, and T. Tsuruga. 2010b. "Accounting for persistence and volatil4 ity of good-level real exchange rates: The role of sticky information." Journal of Inter$5 \quad$ national Economics, 51 (5), 48-60.

Crucini, M. J., M. Shintani, and T. Tsuruga. 2013. "Do sticky prices increase the real exchange rate volatility at the sector level?" European Economic Review, 62, 58-72.

Disdier, A-C. and K. Head. 2008. "The puzzling persistence of the distance effect on bilateral trade." The Review of Economics and Statistics, 90(1), 37-48.

Eaton, J. and S. Kortum. 2002. "Technology, geography, and trade." Econometrica, 70 (5), 1741-1776.

Engel, C. and J. H. Rogers. 1996. "How wide is the border?" American Economic Review, 86 (5), 1112-1125.

Fukunaga, I. 2007. "Imperfect common knowledge, staggered price setting, and the effects of monetary policy." Journal of Money, Credit and Banking, 39 (7), 1711-1739.

Grossman, G. M. 1998. "Comment on Deardorff." In The Regionalization of the World Economy, Frankel J. A. (ed.) University of Chicago Press, 29-31.

Helpman, E., M. Melitz, and Y. Rubinstein. 2008. "Estimating trade flows: Trading partners and trading volumes." Quarterly Journal of Economics, 123 (2), 441-487.

Huang, K. X. D., Z. Liu, and L. Phaneuf. 2004. "Why does the cyclical behavior of real wages change over time?" American Economic Review, 94 (4), 836-856.

Hummels, D. 2001. "Toward a geography of trade costs." Unpublished manuscript.

Kano, K., T. Kano, and K. Takechi. 2013. "Exaggerated death of distance: Revisiting distance effects on regional price dispersions." Journal of International Economics, 90 (2), 403-413. 
1 Kehoe, P. J. and V. Midrigan. 2007. "Sticky prices and sectoral real exchange rates." Federal Reserve Bank of Minneapolis Working Paper No. 656.

Lucas, R. E. 1972."Expectations and the neutrality of money." Journal of Economic Theory, $4(2), 103-124$.

Mankiw, G. and R. Reis. 2002. "Sticky information versus sticky prices: A proposal to replace the New Keynesian Phillips curve." Quarterly Journal of Economics, 117 (4), 1295-1328.

Nakamura, E. and J. Steinsson. 2008. "Five facts about prices: A reevaluation of menu cost models." Quarterly Journal of Economics, 123 (4), 1415-1464.

Obstfeld M. and A. M. Taylor. 1997. "Nonlinear aspects of goods-market arbitrage and adjustment: Heckscher's commodity points revisited." Journal of the Japanese and International Economies, 11 (4), 441-479.

Parsley, D. C. and S.-J. Wei. 1996. "Convergence to the law of one price without trade barriers or currency fluctuations," Quarterly Journal of Economics, 111 (4), 1211-1236.

Parsley, D. C. and S.-J. Wei. 2001. "Explaining the border effect: The role of exchange rate variability, shipping costs, and geography." Journal of International Economics, 55 (1), 87-105.

Phelps, E. S. 1970. "Introduction: The new microeconomics in employment and inflation theory." In Microeconomic Foundations of Employment and Inflation Theory. NY :Norton.

Woodford, M. 2003. "Imperfect common knowledge and the effects of monetary policy." In: Aghion, P., Frydman, R. Stiglitz, J., Woodford, M. (ed.). Knowledge, Information, and Expectations in Modern Macroeconomics: In Honor of Edmund S. Phelps. Princeton University Press, Princeton.

Yazgan, M. E. and H. Yilmazkuday 2011. "Price-level convergence: New evidence from U.S. cities." Economics Letters, 110 (2), 76-78. 
Table 1: Summary statistics

\begin{tabular}{|c|c|c|c|c|c|}
\hline & \multicolumn{3}{|c|}{ Persistence measure } & \multicolumn{2}{|c|}{ Volatility measure } \\
\hline & $\rho_{q}$ & SAR & Largest AR root & $s d_{q}$ & $\operatorname{mapd}_{q}$ \\
\hline \multirow[t]{2}{*}{ All } & 0.520 & 0.534 & 0.542 & 0.136 & 0.158 \\
\hline & $(0.151)$ & $(0.149)$ & $(0.147)$ & $(0.038)$ & $(0.045)$ \\
\hline$($ Obs. $=63,648)$ & {$[0.238]$} & {$[0.244]$} & {$[0.246]$} & {$[0.057]$} & {$[0.089]$} \\
\hline \multirow[t]{2}{*}{ Less than 100 miles } & 0.482 & 0.493 & 0.503 & 0.127 & 0.127 \\
\hline & $(0.174)$ & $(0.173)$ & $(0.166)$ & $(0.040)$ & $(0.046)$ \\
\hline$($ Obs. $=624)$ & {$[0.250]$} & {$[0.254]$} & {$[0.250]$} & {$[0.056]$} & {$[0.076]$} \\
\hline \multirow[t]{2}{*}{ More than 2,000 miles } & 0.563 & 0.578 & 0.585 & 0.150 & 0.243 \\
\hline & $(0.145)$ & $(0.147)$ & $(0.147)$ & $(0.045)$ & $(0.108)$ \\
\hline$($ Obs. $=3,648)$ & {$[0.222]$} & {$[0.229]$} & {$[0.233]$} & {$[0.061]$} & {$[0.149]$} \\
\hline
\end{tabular}

NOTES: Reported numbers are the averages of the estimated persistence and volatility measures over goods and services where the total number of observations is denoted by "Obs." The LOP deviations, $q_{j, k, t}(i)$, are calculated as the logarithm of the relative price of a good or service in a city to the same good or service in a different city. The sample period is over 1990:Q1 - 2007:Q4. Persistence measures are the first-order autocorrelations $\left(\rho_{q}\right)$, the sum of autoregressive coefficients (SAR), and the largest autoregressive root (Largest AR root). The AR order is selected based on the BIC. Volatility measures are the standard deviation $\left(s d_{q}\right)$ and mean absolute price difference $\left(\operatorname{mapd}_{q}\right)$. The numbers in parentheses are the between-group standard deviations across 48 items. The numbers in brackets are the total standard deviations. The upper panel shows statistics for all observations. The middle and lower panels show statistics among city pairs with distance being less than 100 miles and with distance being more than 2,000 miles, respectively. 


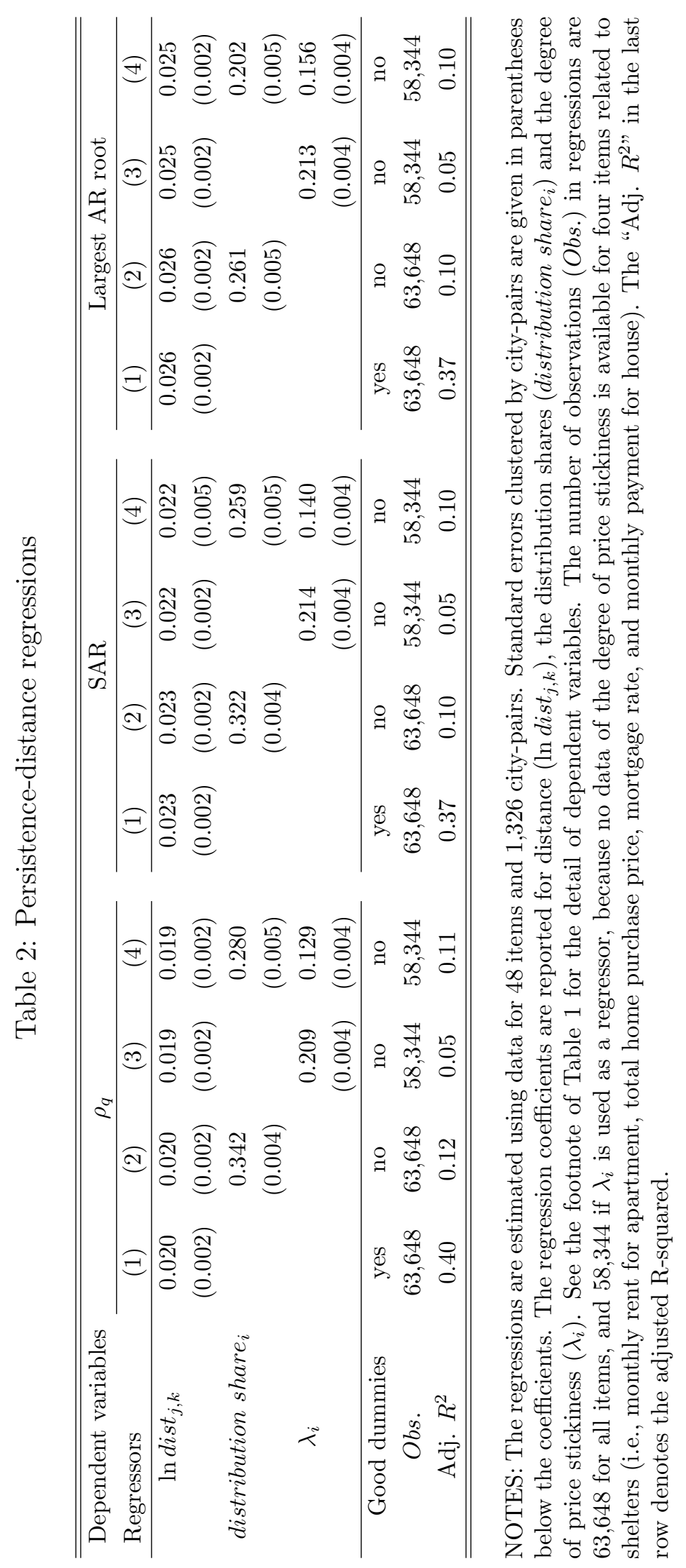


Table 3: Calibrated regression slope in persistence-distance regressions

\begin{tabular}{|c|c|c|c|c|c|c|c|}
\hline & \multicolumn{5}{|c|}{$\kappa$} & \multicolumn{2}{|c|}{$\kappa$ consistent with data } \\
\hline & 0.20 & 0.40 & 0.50 & 0.60 & 0.80 & LB & UB \\
\hline \multicolumn{8}{|l|}{ A: The flexible price model } \\
\hline$\alpha=0.90, \rho_{z}(i)=0.60$ & 0.000 & 0.001 & 0.001 & 0.002 & 0.004 & - & - \\
\hline$\alpha=0.45, \rho_{z}(i)=0.60$ & 0.003 & 0.013 & 0.019 & 0.026 & 0.041 & 0.449 & 0.570 \\
\hline$\alpha=0.00, \rho_{z}(i)=0.60$ & 0.007 & 0.024 & 0.034 & 0.044 & 0.061 & 0.319 & 0.405 \\
\hline$\alpha=0.00, \rho_{z}(i)=0.30$ & 0.003 & 0.012 & 0.017 & 0.022 & 0.030 & 0.483 & 0.648 \\
\hline$\alpha=0.00, \rho_{z}(i)=0.90$ & 0.010 & 0.036 & 0.051 & 0.066 & 0.091 & 0.255 & 0.320 \\
\hline \multicolumn{8}{|c|}{ B: The sticky price model $\left(\alpha=0.00, \rho_{z}(i)=0.60\right)$} \\
\hline$\lambda_{i}=0.35$ & 0.005 & 0.017 & 0.024 & 0.031 & 0.043 & 0.392 & 0.506 \\
\hline$\lambda_{i}=0.65$ & 0.004 & 0.012 & 0.017 & 0.021 & 0.028 & 0.479 & 0.669 \\
\hline$\lambda_{i}=0.95$ & 0.004 & 0.005 & 0.004 & 0.004 & 0.003 & - & - \\
\hline \multicolumn{8}{|c|}{ C: The three-city, flexible price model $\left(\alpha=0.00, \rho_{z}(i)=0.60\right)$} \\
\hline$\left(\tau_{1,2}, \tau_{1,3}, \tau_{2,3}\right)=(0.2,0.2,0.2)$ & 0.016 & 0.047 & 0.060 & 0.068 & 0.074 & 0.197 & 0.251 \\
\hline$\left(\tau_{1,2}, \tau_{1,3}, \tau_{2,3}\right)=(0.2,0.3,0.1)$ & 0.012 & 0.037 & 0.047 & 0.055 & 0.063 & 0.234 & 0.300 \\
\hline \multicolumn{8}{|c|}{ D: The three-city, sticky price model $\left(\alpha=0.00, \rho_{z}(i)=0.60, \lambda_{i}=0.65\right)$} \\
\hline$\left(\tau_{1,2}, \tau_{1,3}, \tau_{2,3}\right)=(0.2,0.2,0.2)$ & 0.009 & 0.023 & 0.027 & 0.030 & 0.030 & 0.298 & 0.425 \\
\hline$\left(\tau_{1,2}, \tau_{1,3}, \tau_{2,3}\right)=(0.2,0.3,0.1)$ & 0.006 & 0.018 & 0.022 & 0.025 & 0.026 & 0.365 & 0.570 \\
\hline
\end{tabular}

NOTES: Each number in the table represents the coefficients for the log-distance in persistence-distance regressions predicted by the noisy information models. The coefficients are obtained from the linear approximation of the theoretical first-order autocorrelation of $q_{t}(i)$ or $q_{2,1, t}(i)=p_{2, t}(i)-p_{1, t}(i)$ around $\bar{\tau}=0.2$, along with the parameter values described in the main text. Lower bound (LB) and upper bound (UB) of $\kappa$ that are consistent with the $95 \%$ confidence interval of regression slope in Table 1 are also shown. Panel A shows the baseline two-city flexible price model. Panel B shows the two-city model with price stickiness. Panels C and $\mathrm{D}$ are the three-city models with and without sticky prices, respectively. In the first rows of Panels $\mathrm{C}$ and D, all trade costs are assumed to be the same across all three city pairs. The second rows of Panels C and $\mathrm{D}$ show the case when trade costs between cities 1 and 2 differ from trade costs between other city pairs. 
Figure 1: Effect of information differences $\kappa$ on persistence and volatility of LOP deviations
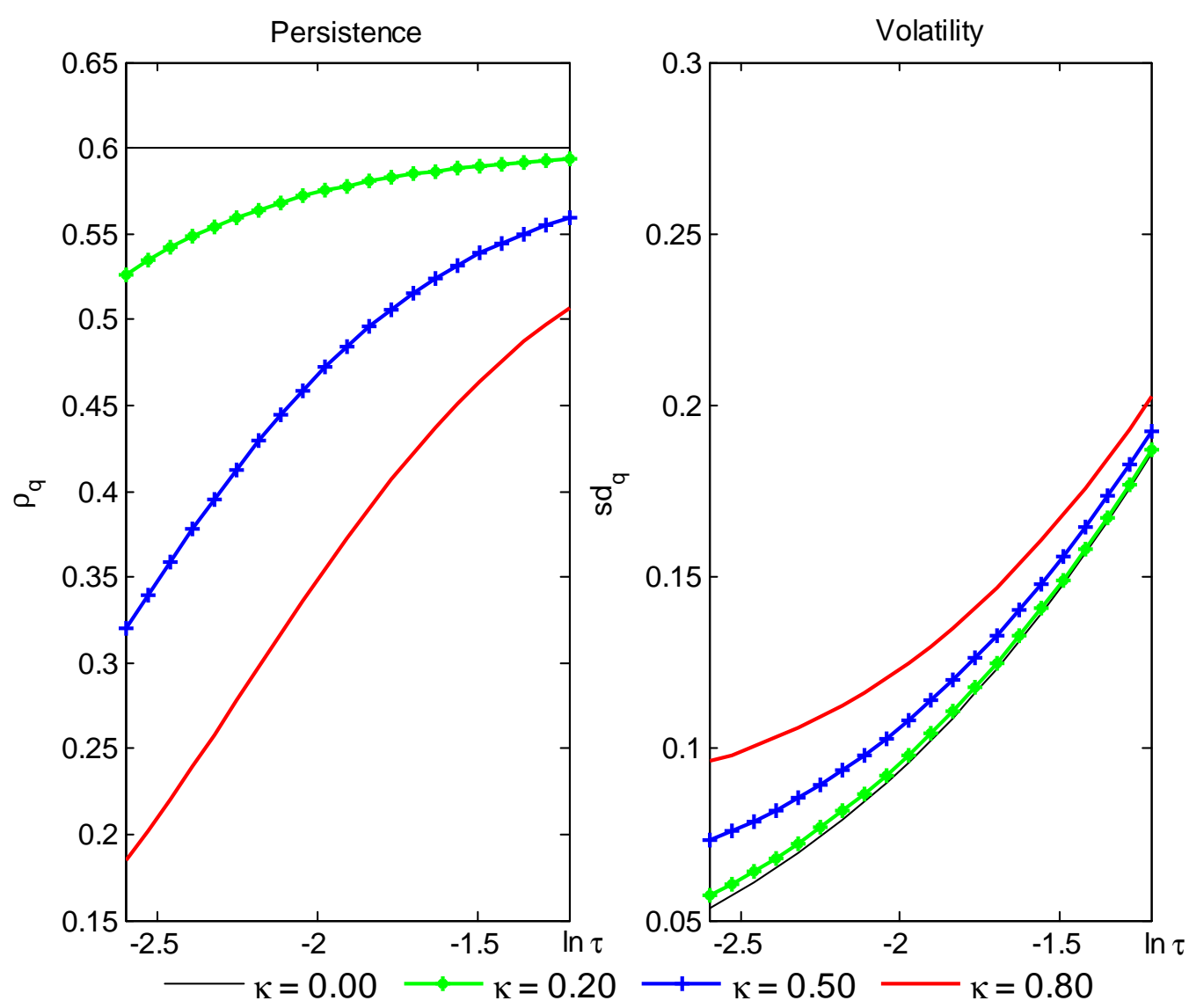

NOTES: Each line in the figure represents the first-order autocorrelation (the left panel) and the standard deviation (the right panel) of $q_{t}(i)$ against $\ln \tau$ for different values of $\kappa$. For parameterization except for $\kappa$, we use $\alpha=0, \rho_{z}(i)=0.6, \bar{\kappa}=0.5, \xi=4, \sqrt{\operatorname{var}\left[z_{t}(i)\right] / \sigma_{\theta}^{2}}=5, \bar{\tau}=0.2$, and $\delta=0.3$. 
Figure 2: Effect of strategic complementarities $\alpha$ on persistence and volatility of LOP deviations

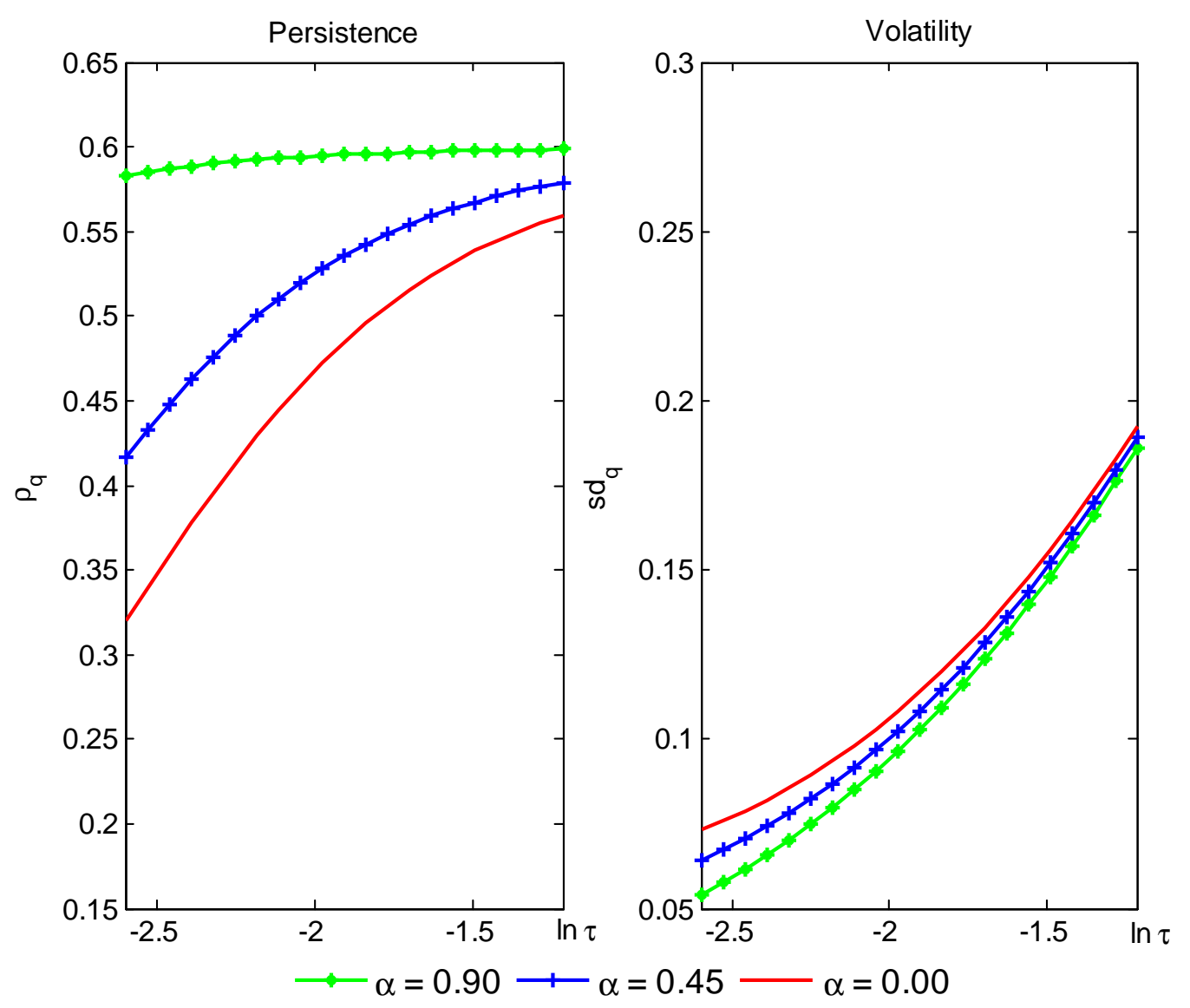

NOTES: Each line in the figure represents the first-order autocorrelation (the left panel) and the standard deviation (the right panel) of $q_{t}(i)$ against $\ln \tau$ for different values of $\alpha$. For parameterization except for $\alpha$, we use $\kappa=0.5, \rho_{z}(i)=0.6, \bar{\kappa}=0.5, \xi=4, \sqrt{\operatorname{var}\left[z_{t}(i)\right] / \sigma_{\theta}^{2}}=5, \bar{\tau}=0.2$, and $\delta=0.3$. 
Figure 3: Effect of the productivity persistence $\rho_{z}(i)$ on persistence and volatility of LOP deviations

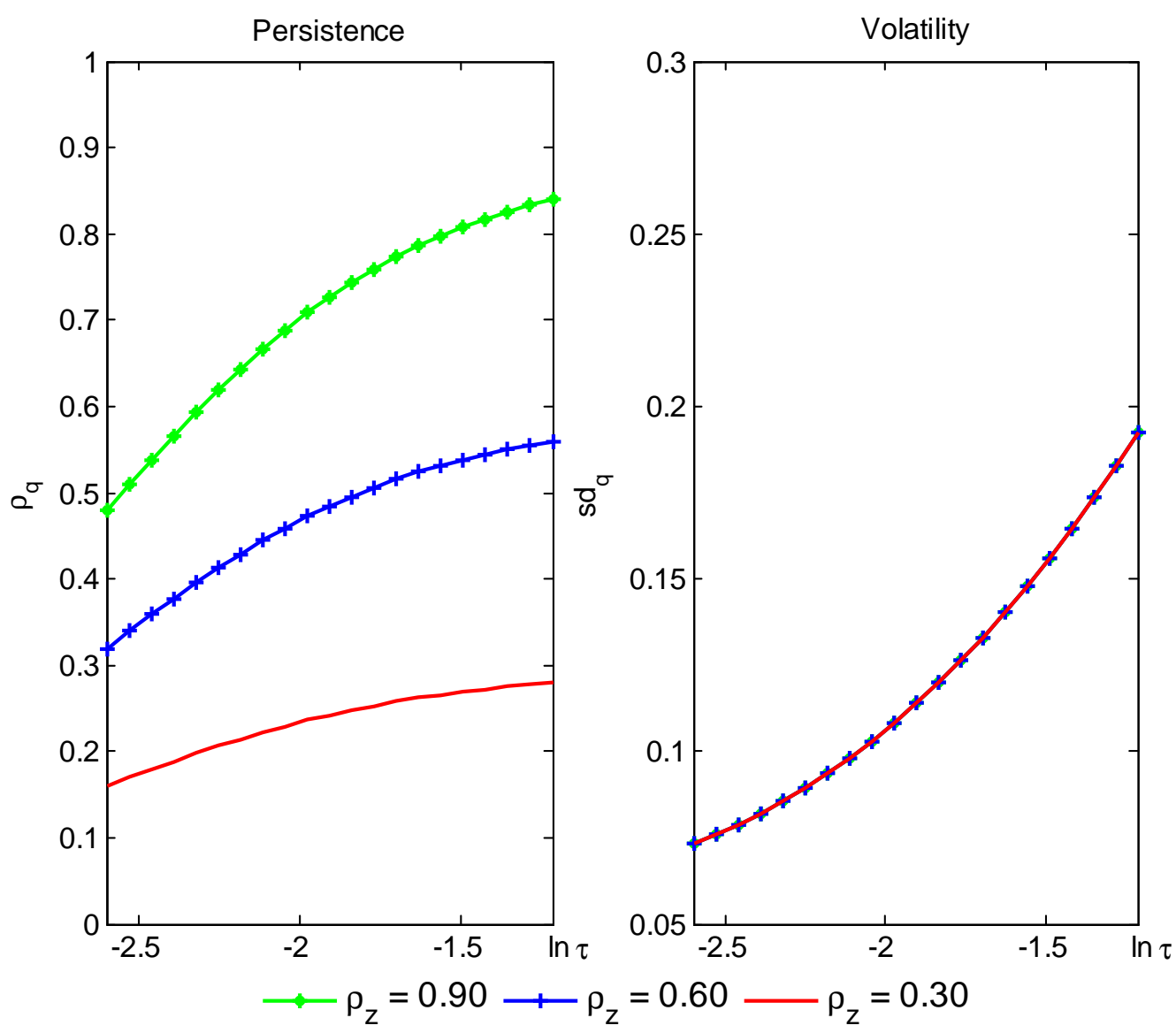

NOTES: Each line in the figure represents the first-order autocorrelation (the left panel) and the standard deviation (the right panel) of $q_{t}(i)$ against $\ln \tau$ for different values of $\rho_{z}(i)$. For parameterization except for $\rho_{z}(i)$, we use $\kappa=0.5, \alpha=0, \bar{\kappa}=0.5, \xi=4, \sqrt{\operatorname{var}\left[z_{t}(i)\right] / \sigma_{\theta}^{2}}=5, \bar{\tau}=0.2$, and $\delta=0.3$. 